\title{
Growth, Characterization and Comparison of Zirconia-Graphite Ceramic Carbon Composites
}

\author{
Veena Kumari ${ }^{1}$, Soni Rani ${ }^{2}$ and Dharvendra Singh $^{3}$ \\ Research Scholarl, Bhagwant University, Ajmer-Rajasthan, India \\ Associate Professor ${ }^{2}$, Bhagwant University, Ajmer-Rajasthan, India \\ Associate Professor ${ }^{3}$, Bhagwant University, Ajmer-Rajasthan, India
}

\begin{abstract}
The density of $\mathrm{ZrO}_{2}$ ceramic carbon composites prepared by the conservative solid sintering technique is as close to any commercially available $\mathrm{ZrO}_{2}$. The Vicker's hardness as well as modulus of the sample with $1400^{\circ} \mathrm{C}$ high temperatures treated, is quite high compared to the lower $1200^{\circ} \mathrm{C} \mathrm{HTT} \mathrm{samples.} \mathrm{From}$ S1 to S6 on comparison, it is found that porosity for S6 is minimum and maximum for S1. After comparing with ceramic monolith the flexural strength and modulus shows a remarkable improvement in its value. The average grain size measured from the width of the $x$-ray peaks, the information highlighted by $x$-ray diffractogram comes from a deeper level of the lattice. The optical micrograph shows the sample was uniform except for asperities arising due to leakage of pitch while carbonizing. The rest of the micrographs help in finding the grain size as well as the extent of infiltration of pitch into the system.
\end{abstract}

Keywords: Ceramic Composites; Porosity; Vicker's hardness; X-ray; micrographs

\section{Introduction}

Zirconia ceramics have several advantages over other ceramic materials, due to the transformation toughening mechanisms operating in their microstructure that can give to components made out of them, very interesting mechanical properties[1]. $\mathrm{ZrO}_{2}$ ceramics are among the oldest oxide-ceramic materials but were refined into a material with high performance properties only fairly recently [2]. A first summary of oxideceramic materials, also those made of $\mathrm{ZrO}_{2}$, was presented after World War II [3]. The transformations between the different polymorphs are important as far as the processing and mechanical properties (strength, toughness, etc.) of zirconia ceramics are concerned. It has been well documented in the literature [4-6]. Pure zirconia is monoclinic $(\mathrm{m})$ at room temperature and pressure. With increasing temperature the material transforms to tetragonal (t), by approximately $1170^{\circ} \mathrm{C}$ and then to a cubic (c) fluorite structure starting about $2370{ }^{\circ} \mathrm{C}$ with melting by $2716{ }^{\circ} \mathrm{C}[7,8]$. Zirconia particles can be embedded in a variety of different matrices to form transformation-toughened ceramics provided the zirconia particles have a sufficiently small size, may be in submicron or below [9]. The increased volume fraction of zirconia is also responsible to reduce the stability of the tetragonal phase [10]. Zirconia has excellent properties for restoration and implantation in dentistry and orthopedics [11]. Zirconia impedes strongest mechanical properties among other ceramics. Due to this property it is widely used in dentistry [12].

\section{Materials And Methods}

$\mathrm{ZrO}_{2}$ (Loba Chemie Pvt., Ltd, India), PVA (Titan biotech limited, Bhiwadi, Rajasthan) and $\mathrm{MnO}_{2}$ (Merck Specialties Private Limited, Mumbai) were procured. The raw materials were weighed in appropriate quantities. The composite were prepared and development by a technique reported earlier by Veena Kumari [13] as per the procedure given in flow diagram Fig.1.

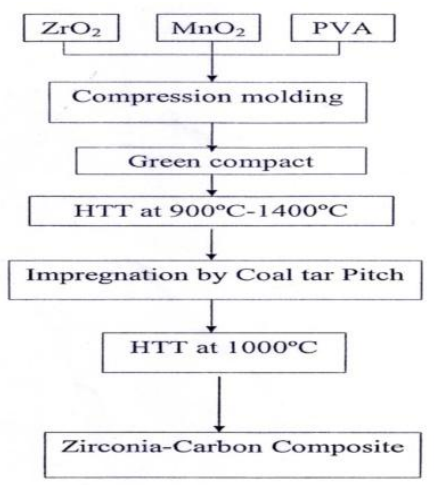

Figure: 1 Flow diagram of processing of zirconia-carbon composite 


\section{RESULT AND DISCUSSION}

Bulk densities of all composite samples $\left(\mathrm{S}_{1}-\mathrm{S}_{6}\right)$ were measure by ASTM standard (ASTM C559) [14] by using the formula:

Bulk Density $=$ weight of the composite $/$ Volume of the composite

Weight of the samples was measured with the help of digital balance (model ME 40290) and volume of the same was taken by measuring the dimensions with the help of digital vernier calipers.

Table 1: The bulk densities of the Zirconia monolith and the composites

\begin{tabular}{|c|c|c|c|c|}
\hline Sample & ZrO $_{\mathbf{2}} \%$ & \multirow{2}{*}{ HTT } & \multicolumn{2}{|c|}{ Bulk density $\left(\mathbf{g} / \mathbf{c m}^{\mathbf{3}}\right)$} \\
\cline { 3 - 5 } & & & Monolith & Zirconia-carbon \\
\hline $\mathrm{S}_{1}$ & 50 & 1200 & 2.37 & 3.12 \\
\hline $\mathrm{S}_{2}$ & 55 & 1200 & 2.98 & 3.25 \\
\hline $\mathrm{S}_{3}$ & 60 & 1200 & 3.10 & 3.25 \\
\hline $\mathrm{S}_{4}$ & 50 & 1400 & 2.76 & 3.14 \\
\hline $\mathrm{S}_{5}$ & 55 & 1400 & 3.06 & 3.35 \\
\hline $\mathrm{S}_{6}$ & 60 & 1400 & 3.45 & 3.70 \\
\hline
\end{tabular}

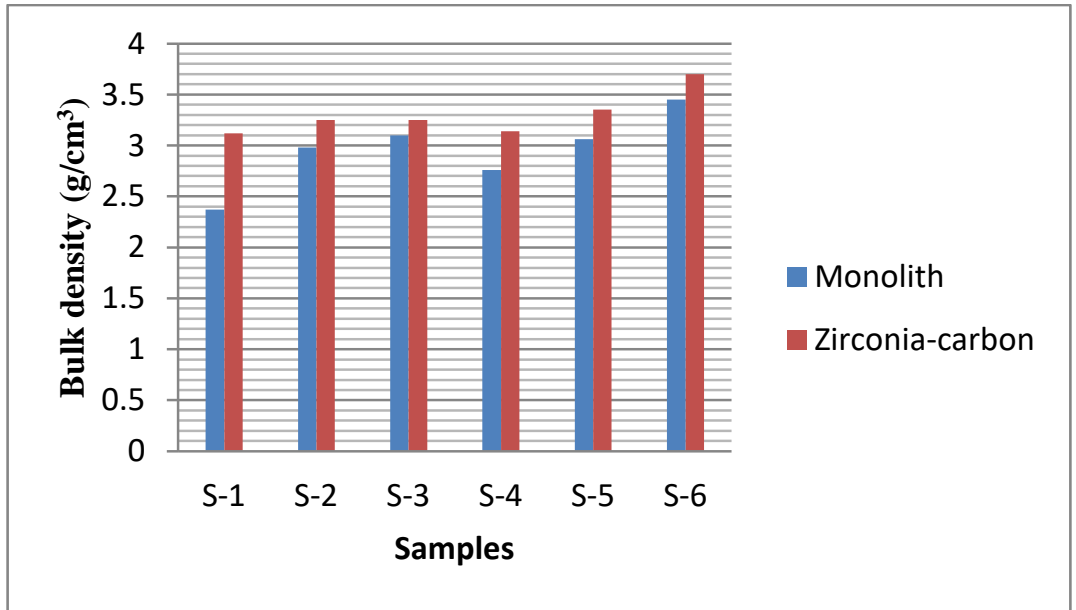

Figure 2: Densities of the $\mathrm{ZrO}_{2}$ monoliths and composites

From the data given in the table 1 we can define that the density of the composite with respect to the monolith is higher from sample S1 to S6. From the table1 and figure 2 it is clear that the density of S6 is higher than that of S1.The graph of density increased in case of S1 to S3 than decreased for S4 and again increased from S4 to S6. Similar pattern was found in case of monolith. The difference in density with pitch infiltrated and carbonized porous zirconia monolith is mildly decreasing with higher volume percentage of $\mathrm{ZrO}_{2}$, this implies the carbon infiltration into the monoliths is greater for S1 and S4 and least for S3 and S6.

To measure the porosity of the samples, kerosene densities of the composite samples are measured first. The kerosene density of the different porous zirconia monolith was measured by the kerosene pick-up method as per Archimedes's principle. The density has been calculated as follows:

Where, As - Weight of solid body in air

$$
\text { Density of Kerosene } \rho(\mathrm{K})=\frac{\mathrm{A}_{\mathrm{S}}-K_{S}}{V_{S}}
$$

Ks - Weight of solid body in kerosene

The bulk density $(\mathrm{Bd})$ and kerosene density $(\mathrm{Kd})$ of the samples were measured with the help of highly precise digital balance (model ME 40290) applying Archimedes principle. Porosity of the samples (Table-2) can be calculated with the help of the following formula,

$$
\text { Porosity }=\left(1-\frac{B_{d}}{K_{d}}\right) \times 100 \%
$$

Table 2: Porosities of the different samples

\begin{tabular}{|c|c|c|c|}
\hline Samples & $\mathbf{Z r O}_{\mathbf{2}} \%$ & HTT & Porosity \\
\hline $\mathrm{S}_{1}$ & 50 & 1200 & 50.0 \\
\hline $\mathrm{S}_{2}$ & 55 & 1200 & 45.5 \\
\hline $\mathrm{S}_{3}$ & 60 & 1200 & 41.7 \\
\hline $\mathrm{S}_{4}$ & 50 & 1400 & 49.1 \\
\hline $\mathrm{S}_{5}$ & 55 & 1400 & 45.5 \\
\hline $\mathrm{S}_{6}$ & 60 & 1400 & 38.8 \\
\hline
\end{tabular}




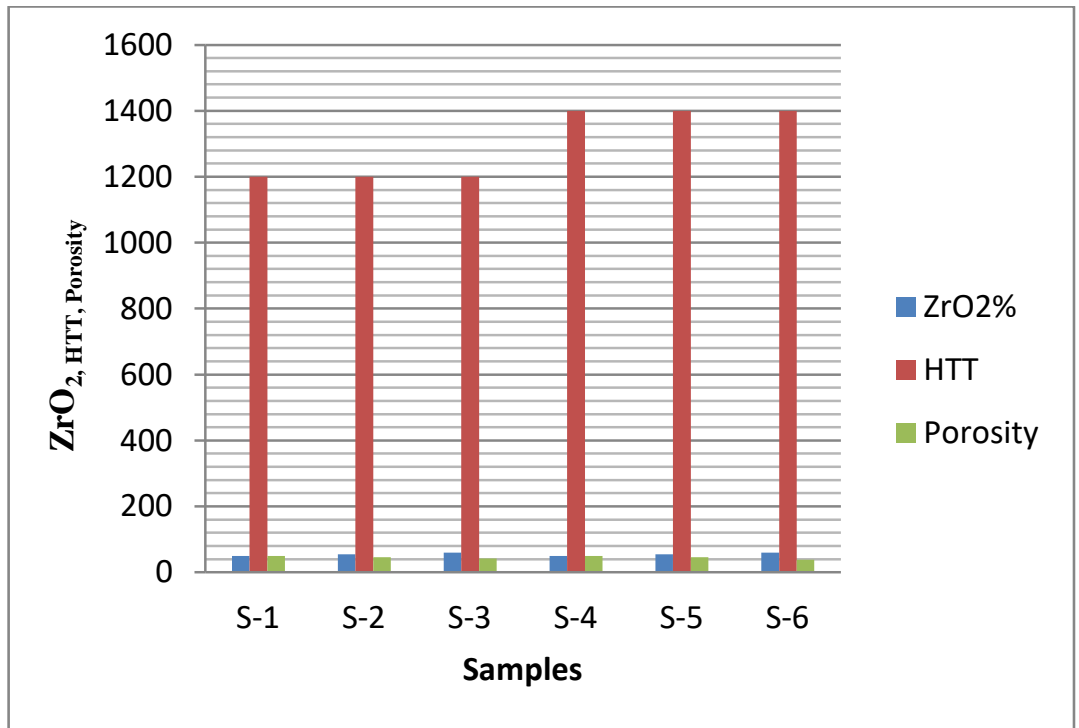

Figure 3: Porosities of the different samples

From the data it is clear that the porosity for S6 is minimum and maximum for S1. The flexural strength, hardness, etc (mechanical properties) were carried out on the samples. The values of the respective parameters have been tabulated in the (Table- 3).

Table 3: Values of Vicker's hardness and the modulus of the samples.

\begin{tabular}{|c|c|c|}
\hline \multirow{2}{*}{ Samples } & Modulus & $\begin{array}{c}\text { Vickers hardness } \\
(\mathbf{H v})\end{array}$ \\
\cline { 2 - 3 } & $\mathbf{G p a}$ & $\mathbf{K g} / \mathbf{m m}^{\mathbf{2}}$ \\
\hline $\mathrm{S}_{1}$ & 8.5 & 50 \\
\hline $\mathrm{S}_{2}$ & 9.0 & 60 \\
\hline $\mathrm{S}_{3}$ & 12.0 & 65 \\
\hline $\mathrm{S}_{4}$ & 14.0 & 194 \\
\hline $\mathrm{S}_{5}$ & 16.5 & 340 \\
\hline $\mathrm{S}_{6}$ & 19.0 & 475 \\
\hline \multicolumn{2}{|c}{} \\
\hline
\end{tabular}

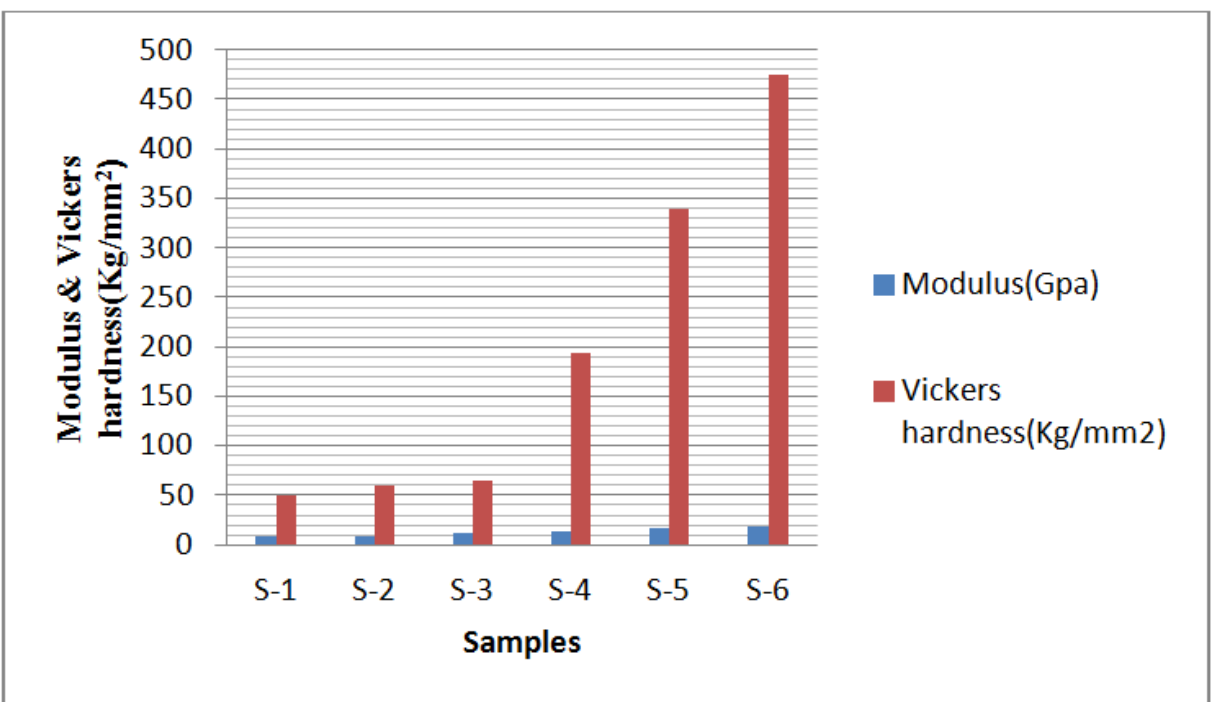

Figure 4: Vicker's hardness and the modulus of the samples

The mechanical properties of the ceramic are tabulated as well as graphically presented which indicates that the Vicker's hardness as well as modulus of the sample with $1400^{\circ} \mathrm{C}$ HTT is quite high compared to the lower $1200^{\circ} \mathrm{C}$ HTT samples. On comparing with ceramic monolith the flexural strength and modulus shows a remarkable improvement in its value. 


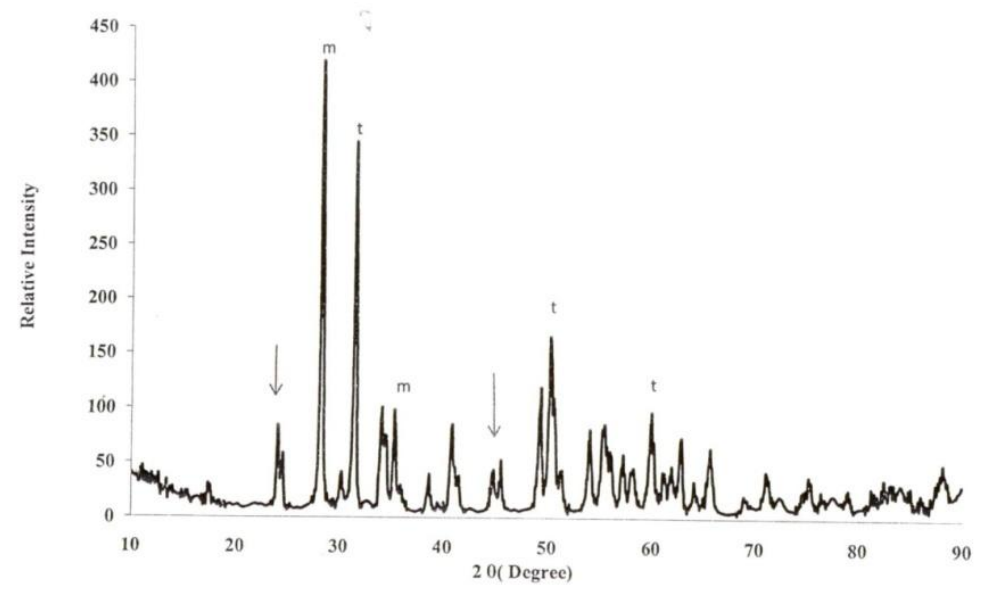

Figure 5: $X$-ray diffractogram of the composite sample $S 1,{ }^{\prime} m$ ' indicates monoclinec and ' $t$ ' indicates tetragonal $\mathrm{ZrO}_{2}$ peaks. The arrows pointed downwards indicate the peaks for carbon (graphitic).

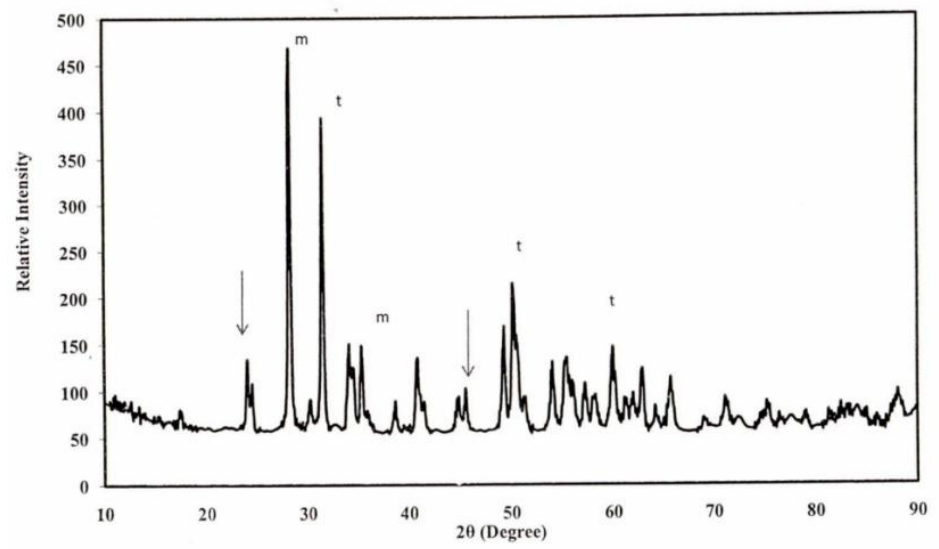

Figure 6: $X$-ray diffractogram of the composite sample $S 4$, ' $m$ ' indicates monoclinec and 't' indicates tetragonal $\mathrm{ZrO}_{2}$ peaks. The arrows pointed downwards indicate the peaks for carbon (graphitic).

It can be seen from the X-ray diffractograms [15](Figures 5 and 6) that the composite possesses crystalline character as is evident from the $\mathrm{X}$-ray peaks. The arrow shown at around 29 values $25^{\circ}$ and $35^{\circ}$ indicates the presence of crystalline carbon (graphite) formed during carbonization of pitch at high temperatures in the absence of oxygen environment. The intense peaks at 29 , values of $27^{\circ}$ and $31^{\circ}$ peaks implies monoclinic and tetragonal $\mathrm{ZrO}_{2}$. This implies that the ceramic monolith is a mixture of two crystal phases of $\mathrm{ZrO}_{2}$.

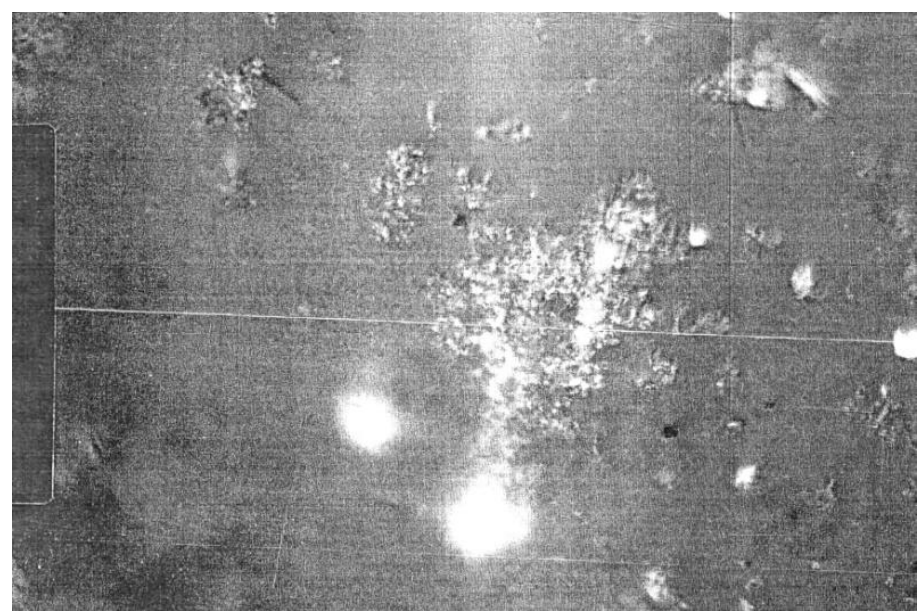

Figure 7: Optical micrograph of the composite sample S3, showing asperities on the surface. 


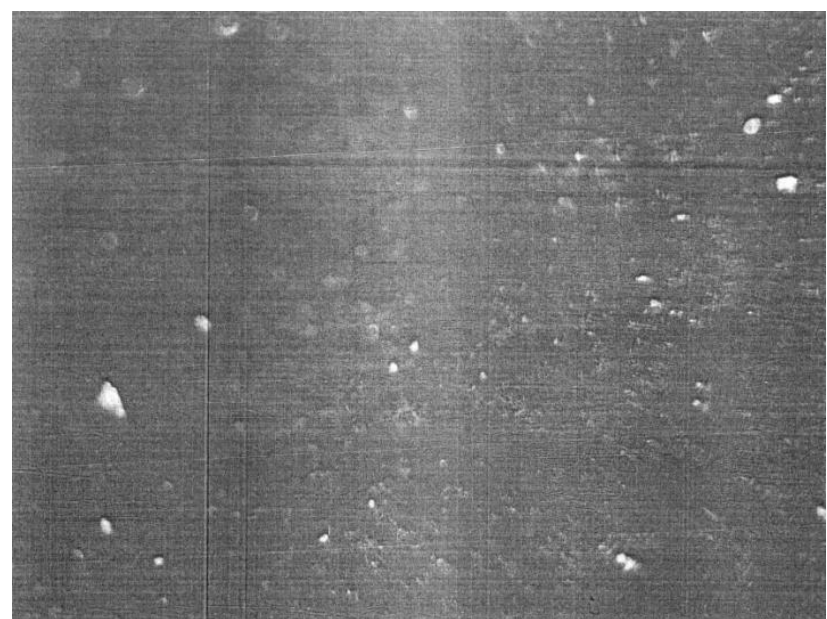

Figure 8: Optical micrograph of the composite sample S6, showing asperities on the surface.

Optical micrograph of the sample was recorded and given in figures 7 and 8, the optical micrograph shows the sample was uniform except for asperities arising due to leakage of pitch while carbonizing.

\section{Conclusions}

From the densities of the samples it can be seen that the apparent density of $\mathrm{ZrO} 2$ ceramic prepared by the conventional solid sintering technique is as close to any commercially available ZrO2. The Vicker's hardness as well as modulus of the sample with $1400^{\circ} \mathrm{C} 5$ high temperatures treated (HTT)? quite high compared to the lower $1200^{\circ} \mathrm{C}$ HTT samples. On comparing with ceramic monolith the flexural strength and modulus shows a remarkable improvement in its value. The average grain size measured from the width of the $\mathrm{x}$-ray peaks, the information highlighted by x-ray diffractogram comes from a deeper level of the lattice. This can be rightly estimated from the $\mathrm{x}$-ray diffractogram that there is a line broadening result which is the effect of fine grain size. The optical micrograph shows the sample was uniform except for asperities arising due to leakage of pitch while carbonizing. The porosity it shows is actually a three dimensional network, which is conducive to infiltration of pitch, also the capillary size roughly calculated and also allows to adjust the vacuum needed to aid good suction of pitch solution into the monolith.

\section{Acknowledgement}

We are grateful to Dr. Sumit Kumar for guiding me in the entire research process. I am also grateful to Bhagwant University, Rajasthan for giving me a chance to pursue my $\mathrm{Ph} . \mathrm{D}$.

\section{References}

[1]. C. Piconi and G. Maccauro, Zirconia as a ceramic biomaterial, Biomaterials, 20 (1), 1999, 1-25.

[2]. A. R eckziegel, Properties and applications of high-performance ceramics made of zirconia, technical paper, Friatec, Revision, 2015 .

[3]. E. Ryshkewitch, Oxidkeramik der Einstoff-Systeme, Springer-Verlag, Berlin 1948

[4]. Q. L Ge, T. C Lei, J. F Mao and Y. Zhou, In situ transmission electron microscopy observations of the tetragonal-to-monoclinic phase transformation of $\mathrm{ZrO}_{2}$ in $\mathrm{Al}_{2} \mathrm{O}_{3}-\mathrm{ZrO}_{2}$ composites; J. Mat. Sc. Lett., 12, 1993, 819.

[5]. D. J Green, R.H.J Hannink, M.V Swain, Transformation toughening of ceramics. Boca Raton, Fla, CRC, 1989.

[6]. J. A Pask, and A. G. Evansed, Ceramic Microstructures, University Conference on Ceramics; $N Y, 1987,433-446$.

[7]. E.C Subbarao, Zirconia-an overview, Science and technology of zirconia, Columbus, OH: The American Ceramic Society; 1981, 124.

[8]. J.P Goff, W. Hayes, S. Hull, M.T Hutchings, K.N Clausen, Defect structure of yttria-stabilized zirconia and its influence on the ionic conductivity at elevated temperatures. Phys. Rev. B, 59(22),1999, 14202-14219.

[9]. R.C Garvie, Critical Size Effects in Alumina-Zirconia Alloys, Advanced in Ceramics, Science and Technology of Zirconia III, The Am. Ceram. Soc., Vol 24, 1988, 55-69.

[10]. D.P Burke, W.M Rainforth, Intermediate rhombohedral $\left(\mathrm{r}-\mathrm{ZrO}_{2}\right)$ phase formation at the surface of sintered Y-TZP's; J. Mat. Sc. Lett. 16, 1997, 883-885.

[11]. M. Bashir et al, Stabilization of Zirconia Ceramics for Dental Coatings - Effect of Aging Conditions, Advances in Civil, Environmental and Materials Research, 2016.

[12]. M.A Basílio, K.V Cardoso, S.G Antonio, A.S Rizkalla, G.C.S Junior, and J.N.A Filho, "Effects of artificial aging conditions on yttria-stabilized zirconia implant abutments", J. Prosthet. Dent., 116, 2016, 277-285.

[13]. V. Kumari and D. Singh, Preparation, growth and characterization of Zirconia-graphite ceramic carbon composites, IJIFR/V4/ E3/ 055, ISSN: 2347-1697, 2016.

[14]. ASTM C 559 Annual Book of ASTM Standards, West Conshohocken, PA, American Society for Testing \& Materials, Vol. $15.01,2001$.

[15]. B. D. Cullity Elements of X-ray diffraction, Addison- Wesley Publishers, 1977. 